\title{
Prenatal Diagnosis and Management of Fetal Goiter Treated Successfully with Intra-Amniotic Levothyroxine
}

\author{
Valentina Corda, Cristina Peddes, Ambra Iuculano, Giovanni Monni* \\ Department of Obstetrics and Gynecology, Prenatal and Preimplantation Genetic Diagnosis, Fetal Therapy, Microcitemico \\ Pediatric Hospital, Cagliari, Italy \\ Email: cordavale@hotmail.it, cristina.peddes@gmail.com, ambraiuculano76@gmail.com, *prenatalmonni@tiscali.it
}

How to cite this paper: Corda, V., Peddes, C., Iuculano, A. and Monni, G. (2021) Prenatal Diagnosis and Management of Fetal Goiter Treated Successfully with Intra-Amniotic Levothyroxine. Open Journal of Obstetrics and Gynecology, 11, 48-52.

https://doi.org/10.4236/ojog.2021.111006

Received: August 31, 2020

Accepted: January 23, 2021

Published: January 26, 2021

Copyright () 2021 by author(s) and Scientific Research Publishing Inc. This work is licensed under the Creative Commons Attribution International License (CC BY 4.0).

http://creativecommons.org/licenses/by/4.0/

(c) (i) Open Access

\begin{abstract}
Goiter is an enlargement of the thyroid gland which can be associated with a number of complications both for the mother and the fetus. A 34-year-old pregnant woman with normal thyroid function was referred to our Department of Obstetrics and Gynecology at Microcitemico Pediatric Hospital, Cagliari, for suspected fetal goiter at 32 gestational weeks. The case was monitored regularly by ultrasound and treated successfully with intra-amniotic levothyroxine (L-T4) administration. Fetal goiter was observed to decrease after this treatment and the thyroid ultrasound findings were also normal both at birth and in subsequent follow-ups. Our case report confirms the feasibility of conservative treatment with L-T4, which can effectively prevent complications related to fetal goiter.
\end{abstract}

\section{Keywords}

Fetal Goiter, Prenatal Diagnosis, Prenatal Therapy, Amniocentesis, Fetal Thyroid, Fetal Ultrasound, Levothyroxine (L-T4)

\section{Introduction}

Goiter is a thyroid gland enlargement. Goiter diameters and vascularity, measurement of the trachea [1] and fetal swallowing should be evaluated during the ultrasound scan [2]. Incidence of fetal goiter is 1 in 40,000 deliveries [3] and it can be associated with hyperthyroidism, hypothyroidism or an euthyroid state.

The most common cause of fetal goiter is maternal assumption of antithyroid drugs. Fetal goiter is also responsible for about $10 \%-15 \%$ of fetuses with congenital hypothyroidism [4]. 
Other conditions associated with fetal goiter are: dysgenesis, dyshormonogenesis, transplacental passage of maternal antibodies, thyroid stimulating hormone receptor mutations, and tumors [5]. In fact, although most cases of fetal goiter are associated with maternal thyroid dysfunction, some cases of euthyroid pregnant women are reported too [6].

Previous reports on fetal goiter hypothyroidism treated with intra-amniotic levothyroxine (L-T4) showed that patients who had intra-amniotic L-T4 administration were likely to have a favourable outcome compared with patients who did not [7].

\section{Case Presentation}

We present a case of a 34-year-old pregnant woman with normal thyroid function, referred to the Department of Obstetrics and Gynecology, Prenatal and Preimplantation Genetic Diagnosis, Fetal Therapy at Microcitemico Pediatric Hospital, Cagliari, for suspected fetal goiter at 32 gestational weeks with normal biometrics and mild polyhydramnios (Amniotic Fluid Index (AFI) $22 \mathrm{~cm}$ ). A parenchymal bilobata mass located between the two carotides, the trachea and the cervical vertebrae in the fetal neck was observed.

Our ultrasound findings confirmed fetal goiter. No sonographic signs suggestive of a fetal thyroid disfunction of the other apparatuses such as cardiac hypertrophy, tachycardia, heart block, hydrops, intrauterine growth restriction, advanced bone age with craniosynostosis and hepatosplenomaegaly were present.

The mass measured $47 \times 29.5 \mathrm{~mm}$ and had peripheral vascularization.

The patient was informed about her diagnosis and counselled about the possible complications.

Cordocentesis was recommended for the assessment of the fetal thyroid function and was performed at 32 weeks. After two needle insertions, $3 \mathrm{ml}$ of clear sample were sampled. Two thyroid-stimulating hormones, free triiodothyronine and free thyroxine, were found in the fetal blood sample and this suggested fetal hypothyroidism: FT3 $<1.00$ pg/ml FT4 $0.42 \mathrm{TSH}>75.0 \mathrm{TG}>300 \mathrm{ng} / \mathrm{ml}$.

Considering the thyroid hormone dosages both of the fetus and the mother, the most probable cause could be congenital dyshormonogenesis due to gene defects involved in the pathway of thyroid hormone production.

Intra-amniotic administration of $300 \mu \mathrm{g}$ of L-thyroxin was performed at 34 gestational weeks.

AFI values were normalized progressively in subsequent evaluations and fetal goiter was observed to decrease after the treatment. Initially, it measured $45 \times 23$ $\times 25 \mathrm{~mm}$ and then $42 \times 22 \times 24 \mathrm{~mm}$ at 35 and 36 weeks of gestation, respectively and these dimensions remained unvariated at the following sonographic check-ups. The last check-up was performed at 38 weeks of gestation and it was regular.

A male newborn of $3250 \mathrm{~g}$ was delivered at 40 weeks by Cesarean section due to maternal issues. No respiratory distress was detected at birth, both the growth and development were normal at the one-month, one-year and five-year fol- 
low-ups. The ultrasound and color Doppler findings of the thyroid size were also normal both at birth and in subsequent follow-ups.

Since this is a case report of a single case studied retrospectively, our hospital institution does not require the approval of the Ethics Committee. A written informed consent has been obtained by the patient prior the intra-amniotic L-T4 administration and for reporting the case.

\section{Discussion}

The ultrasound view of the fetal thyroid should be obtained by an axial scan of the neck, with anterior view of the thyroid between the two jugular veins, in front of the trachea and the posterior position of the vertebra.

The head of the fetus must be slightly hyperextended and this can be a possible setback for obtaining an optimal scan. The visualization of the thyroid is usually facilitated by concurrent pathological processes, such as goiter.

The ultrasound identification of a solid, anterior, and symmetrical neck mass resulting in hyperextension of the fetal head requires further investigation of fetal hormone levels to establish the exact diagnosis.

Ultrasound scan of the fetal neck generally facilitates a goiter diagnosis but it is not reliably applicable for distinguishing between fetal hypo- and hyperthyroidism [8]. However, an ultrasound score to predict the fetal thyroid function in cases of fetal goiter has recently been formulated. It is based on the color Doppler pattern of fetal goiter, heart rate, bone maturation and mobility [9].

Fetal goiter can also be a cause of complications at delivery such as dystocia by extending the fetal head during labor or acute respiratory failure, if the enlarged gland obstructs the airways [10]. The maternal-fetal management usually requires an experienced multidisciplinary team, including an endocrinologist, obstetricians and a fetal radiologist.

Early fetal diagnosis is essential for the proper neurodevelopment and the prevention of polyhydramnios, tachicardia and goiter-related tracheal and esophageal obstruction [1].

In our case, the intra-amniotic L-T4 administration proved to be an effective method for preventing complications related to fetal goiter and this is confirmed by the reports present in literature so far.

The mechanism of intra-amniotic L-T4 treatment is unclear: it can be absorbed or ingested by the fetus after intra-amniotic administration [11].

The dose of intra-amniotic L-T4 is adjusted according to the estimated fetal weight, with a median dose of $250 \mu \mathrm{g}$ (range $50-600 \mu \mathrm{g}$ ). Adverse effects of its administration include infection, bleeding, preterm labor [9]. Injection of L-T4 into the umbilical vein should be limited only to those situations in which intra-amniotic L-T4 injections have failed [12].

\section{Conclusions}

Our case report confirms the feasibility of conservative treatment of fetal goiter with L-T4 and it complies with a recently published review which affirms that all 
the regimens of administration proposed seemed to have similar results in terms of fetal goiter reduction and thyroid parameters at birth [13].

Further studies are needed to determine the optimal management of this disorder.

\section{Conflicts of Interest}

The authors report no conflicts of interest. The authors alone are responsible for the content and writing of the paper.

\section{References}

[1] Ranzini, A.C., Ananth, C.V., Smulian, J.C., Kung, M., Limbachia, A. and Vintzileos, A.M. (2001) Ultrasonography of the Fetal Thyroid: Nomograms Based on Biparietal Diameter and Gestational Age. Journal of Ultrasound in Medicine, 20, 613-617. https://doi.org/10.7863/jum.2001.20.6.613

[2] Taff, C. (2016) Prenatal Diagnosis and Treatment of Fetal Goiter. Journal of Diagnostic Medical Sonography, 32, 40-43. https://doi.org/10.1177/8756479315613940

[3] Bianchi, D.W., Crombleholme, T.M., D’Alton, M.E. and Malone, F.D. (2000) Goiter. Fetology: Diagnosis and Management of the Fetal Patient. McGraw-Hill, Columbus, 263-268.

[4] Gruner, C., Kollert, A., Wildt, L., Dörr, H.G., Beinder, E. and Lang, N. (2001) Intrauterine Treatment of Fetal Goitrus Hypothyroidism Controlled by Determination of Thyroid-Stimulating Hormone in Fetal Serum: A Case Report and Review of the Literature. Fetal Diagnosis and Therapy, 16, 47-51.

https://doi.org/10.1159/000053880

[5] Pereira, R.C., Barroso, L.M., Mendes, M.J., Joaquim, I.F. and Ornelas, H. (2011) A New Born with Neck Mass. Einstein, 9, 78-80. https://doi.org/10.1590/s1679-45082011rc1891

[6] Neto, J.F.G., Junior, E.A. and Costa, J.I.F. (2016) Fetal Goiter Conservatively Monitored during the Prenatal Period Associated with Maternal and Neonatal Euthyroid Status. Obstetrics \& Gynecology Science, 59, 54-57.

https://doi.org/10.5468/ogs.2016.59.1.54

[7] Kobayashi, M., Yagasaki, H., Saito, T., Naito, A. and Sugita, K. (2017) Fetal Goitrus Hypothyroidism Treated by Intra-Amniotic Levothyroxine Administration: Case Report and Review of the Literature. Journal of Pediatric Endocrinology and Metabolism, 30, 1001-1005. https://doi.org/10.1515/ipem-2017-0094

[8] Panaitescu, A.M. and Nicolaides, K. (2018) Fetal Goitre in Maternal Graves' Disease. Acta Endocrinol (Buchar), 14, 85-89. https://doi.org/10.4183/aeb.2018.85

[9] Huel, C., Guibourdenche, J., Vuillard, E., Ouahba, J., Piketty, M., Oury, J.F. and Luton, D. (2009) Use of Ultrasound to Distinguish between Fetal Hyperthyroidism and Hypothyroidism on Discovery of a Goiter. Ultrasound in Obstetrics \& Gynecology, 33, 412-420. https://doi.org/10.1002/uog.6315

[10] Ogamo, M., Sugiyama, T. and Maeda, Y. (2005) The ex utero Intrapartum Treatment (EXIT) Procedure in Giant Fetal Neck Masses. Fetal Diagnosis and Therapy, 20, 214-218. https://doi.org/10.1159/000083908

[11] Abuhamd, A.Z., Fisher, D.A., Warsof, S.L., Slotnick, R.N., Pyle, P.G., Wu, S.Y., et al. (1995) Antenatal Diagnosis and Treatment of Fetal Goitrus Hypothyroidism: Case Report and Review of the Literature. Ultrasound in Obstetrics \& Gynecology, 6, 
368-371. https://doi.org/10.1046/j.1469-0705.1995.06050368.x

[12] Stoppa-Vaucher, S., Francoeur, D., Grignon, A., Alos, N., Pohlenz, J., Hermanns, P., Van Vliet, G. and Deladoëy, J. (2010) Non Immune Goiter and Hypothyroidism in a 19-Week Fetus: A Plea for Conservative Treatment. The Journal of Pediatrics, 156, 1026-1029. https://doi.org/10.1016/j.jpeds.2010.01.018

[13] Nemescu, D., Tanasa, I.A., Stoian, D.L., Navolan, D.B. and Vinturache, A.E. (2020) Conservative in utero Treatment of Fetal Dyshormonogenetic Goiter with Levothyroxine, a Systematic Literature Review. Experimental and Therapeutic Medicine, 20, 2434-2438. https://doi.org/10.3892/etm.2020.8794 